\title{
Power Generation with Different Types of the Vertical Wind Turbine for Domestic use in Northern Cyprus: A Case Study
}

\author{
${ }^{1,2 *}$ Youssef Kassem, ${ }^{1}$ Huseyin Camur and ${ }^{1}$ Renas Hasan \\ ${ }^{1}$ Department of Mechanical Engineering, Faculty of Engineering, Near East University, \\ 99138 Nicosia, Cyprus \\ ${ }^{2}$ Department of Civil Engineering, Faculty of Civil and Environmental Engineering, \\ Near East University, 99138 Nicosia, Cyprus \\ yousseuf.kassem@neu.edu.tr, +90 (392) 2236464
}

\begin{abstract}
Nowadays, wind energy is one of the most economical energy sources with a well-known technology. Today, wind energy is mainly use to generate electricity. Wind turbines convert the kinetic energy into mechanical or electric power. In addition, wind turbine power production depends on the interaction between the rotor and the wind. The aerodynamic forces generated by wind determine the major aspects of the wind turbine performance, for example, power output and load. The aim of this research is to determine the drag force, torque and mechanical power for different type of vertical wind turbine blades which are an airfoil blade, $\mathrm{C}$-section blade and single big C-section blade in a two-dimensional model and this mechanical power are transmitted to the generator to produce electricity for domestic use in North-Cyprus. In particular, drag force and torque acting on each types of blade was taken at an airflow speed of $4 \mathrm{~m} / \mathrm{sec}$ and an angular velocity of $13.056 \mathrm{rad} / \mathrm{sec}$ according to statistical meteorological. These works allow researcher to make a comparison between aerodynamic characteristics and different types of the blades. The objective of this research in using different types of wind turbines is to maximize the amount of electrical power which is produced by the generator.
\end{abstract}

Key words: Vertical wind turbine blade, drag force, mechanical power, electrical power, produce electricity, aerodynamic

\section{INTRODUCTION}

Wind energy has been proved to be one of the most viable sources of renewable energy. With current technology, the low cost factor of wind energy makes it becomes more competitive in the energy market. Wind energy is a comparably low cost energy harvesting system that can yield an adequate amount of energy to a built environment which is environmental friendly and free from harmful wastes. Rather than gaining energy from non-renewable energy sources such as petroleum and gas, wind is being exploited by wind turbine to become an energy producing mechanism with the knowledge of mechanical engineering and skills (Khan, 2006; Masters and Duff, 2011).

Wind turbine generator that are being used in all over the world today are mostly operates at impelled constant speed operation. This is due to their simplicity of the wind turbine generator to connect to the utility grid without the need of frequency conversion and to assure stable energy supplies (Horiuchi and Kawahito, 2001). Wind turbines are classified into as Horizontal Axis Wind Turbines (HAWT) or Vertical Axis Wind Turbines (VAWT) depending on the orientation of the axis of the rotor rotation (Kothari, 2008). VAWTs may have either drag or lift driven rotors. The most common drag and lift driven VAWT are Savonius and Darrieus, respectively (Manwell et al., 2009).

Wind power produces no harmful emissions and will not be depleted over time. Approximately, $1 \mathrm{MW}$ of wind turbine system can displace more than 3.2 tons of nitrogen oxides, 6.5 tons of sulfur dioxide, 1,500 tons of carbon dioxide and 60 pounds of mercury compared to the average utility generated by fuel mix in United States (Patel, 2006). In the scenario of China, one of the largest countries in the world where wind energy system is much developed, the total capacity of wind turbines installed in the year of 2012 was $75.3 \mathrm{GW}$ with a growth rate of $20.8 \%$ compared to year, 2011.

Corresponding Author: Youssef Kassem, Department of Mechanical Engineering, Faculty of Engineering, Near East University, 99138 Nicosia, Cyprus, yousseuf.kassem@neu.edu.tr, +90 (392) 2236464 
Over the time in the European Union (EU), wind energy is the second largest contributor to the new power source which translates into $30 \%$ share of the net increase of the energy supplies. Wind power in the Europe has demonstrated impressive growth rate over the last years due to its potential to become a non-hydrogen renewable energy sources and low-carbon energy farming systems. The aim of Europe renewable energy directive is to increase the share of renewable energy in the EU from 8.6-20\% in 2005 and 2020, respectively (EWEA, 2011). Onshore wind is the cheapest renewable electricity technology and hence will be the largest contributor of the renewable electricity source needed by EU in 2020 (Kjaer, 2010).

According to European Wind Energy Association's report by year, 2020, wind energy system should meet $15.7 \%$ of EU electricity demand which is $230 \mathrm{GW}$ and increase by $28.5 \%$ reaching to $400 \mathrm{GW}$ by the end of 2030 . That by 2050, wind energy system will able to provide half of Europe's power together with the remainder from other renewable sources (European Wind Energy Association, 2010). Turkey in the other hand is also putting more attention to the development of wind energy system in order to overcome the problem with non-renewable energy sources in future. The country is providing much awareness to the energy industries as 'The Renewable Energy Law' was introduced in 2005. Ever, since, the development of wind energy has aroused and wind energy utilization has been dramatically accelerated as the result of government supports.

At the beginning of January 2014, wind power delivers a growing fraction to the energy production systems and has made up of 5,276 wind turbines with a total installed capacity of over $10 \mathrm{GW}$ : 6,831 MW of onshore capacity and 3,653 MW of offshore capacity in the United Kingdom (Patel, 2006). By 2016, current capacity of wind power industry will increase from $200 \mathrm{MW}$ (in 2001) to $1000 \mathrm{MW}$ which announced by Canadian Government (Tong, 2010).

The aim of this research is to produce power by using the wind energy for domestic purposes of households in North-Cyprus. There is a continuous wind flow through the mountains located along the seaside in the Northern part of the island directing to the inmost of the country. According to Turkish statistical meteorology, the average wind speed is minimum $4 \mathrm{~m} / \mathrm{sec}$ for at least $6 \mathrm{~h} /$ day. The calculations of the parameters are based on this average speed. To determine the mechanical energy, three different types of blades are used. Once, the mechanical energy is obtained it can be converted into electrical energy using Permanent Magnet Synchronous Generator (PMSG). In the foregoing sections, for
NACA-profiles and blades are used, the fundamental theory, namely the airfoil theory for some rotational region and the rest of the region the profiles are considered as a flat plate will be discussed. The equations for calculating the most important parameters, velocity and pressure distributions, lift and drag coefficients, lift, drag and finally, torque and power are derived. The singularity theory is applied in the airfoil theory. For the C-section and single big C-blades the appropriate tables are used for calculating the drag coefficients. Finally, they affect the load transients on the turbine's shaft and the blades characteristics which affect the efficiency and performance of the turbine are discussed.

\section{Theory}

Wind turbine: The aerodynamic force and design of wind turbine are two important criteria for categorizing the wind turbines. Wind turbines are divided into drag based and lift based by considering aerodynamic performance. As low speed turbines, the rotors which utilize the drag force of the wind are recognized. However, in some turbines, the possibility of employing the lift force is also provided. The lift based turbines are recognized as high speed rotors. These are capable of capturing higher amount of the wind power compared to their drag based counterparts and therefore, they are the most common solution today.

Wind turbine can be classified into two types which are Horizontal Axis Wind Turbine (HAWT) and Vertical Axis Wind Turbine (VAWT). The HAWT is the most commercial wind turbine today. The rotating of horizontal axis blades is parallel to the wind speed. The advantages of HAWT are high turbine efficiency, high power density, low cut-in wind speeds and low cost per unit power output. While in the vertical axis, the rotating of blades is perpendicular to the ground. There are several advantages for VAWT such as VAWT can accept wind from any direction and thus, no yaw control is needed (Iida et al., 2004).

Vertical Axis Wind Turbine (VAWT): The studied wind energy converter is a VAWT which is a less common type of wind turbine. The VAWT is Omni-directional, i.e., it accepts wind from all directions and does not need a yawing mechanism. In addition, the vertical axis wind turbine is predictable to produce less noise than a horizontal axis wind turbine (Eriksson, 2008).

The studied system has a turbine with straight blades which are attached to the drive shaft via. support arms. This configuration is commonly called an H-rotor as by Ribrant and Bertling (2007). The simplicity is the main advantage with this wind turbine concept. The wind 
turbine consists of few parts and will only have one rotating part. The omission of the gearbox, yawing system and pitch system is expected to reduce maintenance (Eriksson et al., 2008). The blades will be fixed, i.e., it will not be possible to turn them out of the wind. The absorbed power will be controlled by an electrical control system combined with passive stall control, i.e., the blades will be designed to stall to limit power absorption at high wind speeds.

The generator of the vertical rotational axis of wind turbine is located at the bottom of the tower. This is expected to simplify installation and maintenance. The tower can be lighter for a VAWT, since, the nacelle is excluded which reduces structural loads and problems with erecting the tower. The generator design is focused on efficiency, cost and minimizing maintenance as the size of the generator is not the main concern. In advantage, the control system can also be located at ground level facilitating access (Angelin et al., 1981).

There is an apparent difference in the drive train between a HAWT and a VAWT with a ground based generator (apart from turbine configuration): the length of the drive shaft. The long drive shaft of this type of VAWT is interesting to field of study. Although, the long drive shaft is not unique for this system; it is has been used in hydropower. In Jarnvagsforsen, Sweden, a hydropower station with two turbine-generator systems of the long shaft type was installed, each having a rated power of $60 \mathrm{MVA}$, a drive shaft length of $45 \mathrm{~m}$ and a shaft outer diameter of $1.4 \mathrm{~m}$ (Earnest, 2014).

Working principle of VAWT: In the VAWT design which may be two-bladed, three-bladed or four-bladed, the blades are symmetrically arranged around a vertical axis and the angles of the blades are set optimally in such a manner, so that, it works on the lift principle.

For a rotating VAWT, the blades encounter two forces its own rotating speed and the incoming wind speed (Fig. 1). There is a tangential force pulling the blade around and radial force acting against the bearing of vertical axis. Both speeds get added vectorially yielding a total apparent wind speed at an incoming angle of attack. The incoming air stream which is parallel to the blade yields high and low pressure regions on the blade, yielding overall lift and drag forces. The resulting oblique lift force creates a torque on the shaft to which the blades are attached making them rotate in the direction of the blades in which they are already travelling. The VAWT yield an overall positive torque that can be extracted as electrical power through the generator.

A major limitation of the VAWT is that it is not self-starting due to symmetry of the blades. Hence, to

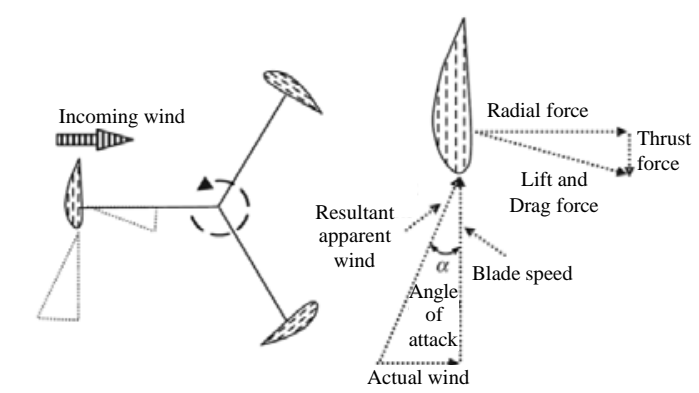

Fig. 1: Lift principle of three-bladed VAWT rotor: the aerofoil of the blades are adjusted

generate a torque on its own, stating is achieved by operating the electrical generator as a motor and then speeding up the VAWT sufficiently for the wind to pass over the blade aerofoils to create the lift force and then run in the generating mode. Torque is caused by change in the apparent wind direction relative to the moving blades (Abzug and Larrabee, 2002).

Airfoil theory: An airplane wing, propeller blades, windmill blades, compressor and turbine blades in a jet engine and hydrofoils have a special shape called an airfoil. An airfoil is a body of such a shape that is placed in an airstream in order to produce an aerodynamic force.

Mathematical formulation for four digit NACA airfoil: An aircraft wing has an NACA airfoil shapes. The NACA airfoils were designed during the period from 1929 through 1947 under the direction of Eastman Jacobs at the NACA's Langley Field Laboratory (Abbott and von Doenhoff, 1959). It is often summarized by a few parameters such as: maximum thickness, maximum camber, position of max thickness, position of max camber and nose radius. Schlichting and Truckenbrodt (1979) describes NACA four digits series and presents the equations for constructing NACA four digits series which describe the thickness distribution and camber lines of the four digits series.

Numerical evaluation of the profile theory: The calculations of the velocity distribution and the aerodynamic coefficients have been derived through the singularity method in the previous section. Now, these parameters can be evaluated in a convenient way through the numerical summation formulas. The details of the calculation are referred to the research of F. Riegels and E. Truckenbrodt (Houghto and Carpenter, 2003).

The velocity distribution on the profile contour at discrete points $X_{n}$ is obtained through the following summation Eq. 1: 


$$
\frac{\mathrm{W}_{\mathrm{k}}\left(\mathrm{X}_{\mathrm{n}}\right)}{\mathrm{U}_{\infty}}=\frac{1}{\mathrm{X}_{\mathrm{n}}^{*}}\left[\begin{array}{l}
\mathrm{a}_{\mathrm{n}}+2 \sum_{\mathrm{m}=1}^{\mathrm{N}-1} \mathrm{~A}_{\mathrm{nm}} \mathrm{Z}_{\mathrm{m}}^{\mathrm{t}} \pm 2 \sum_{\mathrm{m}=1}^{\mathrm{N}-1} \mathrm{C}_{\mathrm{nm}} \mathrm{Z}_{\mathrm{m}}^{\mathrm{s}} \pm \\
\alpha\left(\mathrm{b}_{\mathrm{n}}+2 \sum_{\mathrm{m}=1}^{\mathrm{N}-1} \mathrm{H}_{\mathrm{nm}} \mathrm{Z}_{\mathrm{m}}^{\mathrm{t}}\right)
\end{array}\right]
$$

Where:

$$
X_{n}^{*}=\sqrt{C_{n}+\left(\frac{d Z^{t}}{d \varphi}\right)_{n}^{2}}
$$

and an ,bn , cn, Anm, Cnm and Hnm are Fourier series coefficients and $\mathrm{N}$ is the number of discrete nodes (Houghto and Carpenter, 2003).

Estimation of lift and drag coefficients from pressure coefficient: One way to evaluate the aerodynamic coefficients is to measure the surface pressure distribution and integrate that over the airfoil area. The pressure difference between the lower and upper surface is obtained by means of the Bernoulli equation. Lift and drag coefficients for airfoil section depends on Reynolds number (Drag coefficients for two-dimensional shapes $(104<\operatorname{Re}<106)$. The drag coefficients in all cases are based on the projected area as by Fox et al. (2002)) and angle of attack between the chord line and the undisturbed flow direction. As the angle of attack is increased, the minimum pressure point moves forward on upper surface and the minimum pressure becomes lower. Once the pressure coefficient is calculated, the aerodynamic coefficients which are Lift Coefficient (CL) and Drag Coefficient (CD) can be calculated in-term of pressure coefficients as by Heffley (2007) and Fox et al. (2002).

Lift and drag forces on airfoil: The aerodynamic forces acting on a body may be described by lift and drag. Lift (L) is the net vertical force and Drag (D) is the net horizontal force with respect to the direction of motion. The equations for calculating lift and drag are very similar:

$$
\begin{aligned}
& \mathrm{L}=\frac{1}{2} \rho \mathrm{U}_{\infty}^{2} \mathrm{C}_{\mathrm{L}} \mathrm{A} \\
& \mathrm{D}=\frac{1}{2} \rho \mathrm{U}_{\infty}^{2} \mathrm{C}_{\mathrm{D}} \mathrm{A}
\end{aligned}
$$

Where:

$\mathrm{D}=$ The density of air

$\mathrm{U}_{4}=$ The relative velocity of the airflow

$\mathrm{A}=$ The Area of the airfoil as viewed from an overhead perspective (Anderson and Anderson Jr, 1999)

\section{MATERIALS AND METHODS}

Components of wind electric systems: Wind energy or wind power today is one the most reliable way to generate mechanical power or electricity. Wind power neither produces any toxic emissions nor any heat-trapping emissions that can contribute to global warming and inevitably dangerous. Wind turbines, unlike a working fan in your house that uses electricity to generate wind, use wind power to generate electricity.

The wind turbine rotor assembly is designed to convert mechanical power from the wind into an electrical power output or directly move machines or vehicles. The components of a wind electric generation system are shown in Fig. 2. Permanent Magnet Synchronous Generator (PMSG) is connected to the turbine through a suitable step up gear box and coupling. The generated power variable frequency is fed to the load through power converters designed to ensure constant voltage and frequency. Since, the wind power varies with wind velocity, the generator output voltage and frequency vary continuously. The variable AC output voltage is fed to an $\mathrm{AC}$ to $\mathrm{DC}$ rectifier. An inverter is then used to convert DC voltage of the rectifier into $\mathrm{AC}$ voltage with the desired voltage level and frequency using either hysteresis, sinusoidal PWM or Space vector PWM. The voltage source inverter can be connected directly to a local grid in an on-grid system. This connection ensures the exchange of electrical power between the wind turbine and the electric grid.

Wind turbine model: The two primary types of wind turbine are the Horizontal Axis (HAWT) and Vertical Axis (VAWT) machines. VAWTs has certain advantage over HAWTs which makes it favorable for installation in urban areas, like it gives a better response to turbulent wind flows when installed on buildings (Heffley, 2007). The power that the wind turbine can absorb from the wind is proportional to cross section area of rotor $\mathrm{A}$, the air density, Dat normal conditions, the power Coefficient, $\mathrm{C}_{\mathrm{p}}$ and the cubic of the wind speed $\mathrm{U}_{4}$ as described in Eq. 5 (Bianchi et al., 2007):

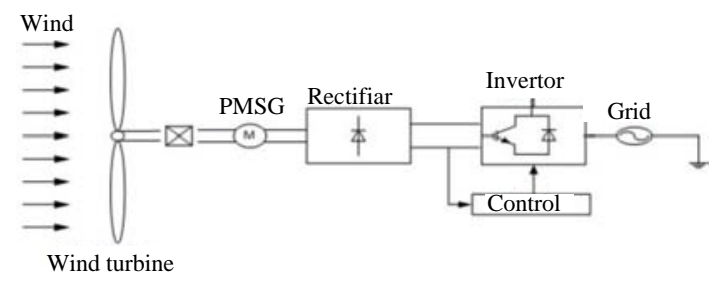

Fig. 2: The main components for wind electric syste 


$$
\mathrm{P}=\frac{1}{2} \rho \mathrm{U}_{\infty}^{3} \mathrm{AC}_{\mathrm{P}}
$$

The aerodynamic torque is expressed as in Eq. 6 (Bianchi et al., 2007):

$$
\mathrm{T}=\frac{1}{2} \rho \mathrm{U}_{\infty}^{3} \mathrm{AC}_{\mathrm{q}}(\lambda)
$$

where, $\mathrm{C}_{\mathrm{q}}(8)$ represents the torque Coefficient and is given in Eq. 7:

$$
\mathrm{C}_{\mathrm{q}}(\lambda)=\frac{\mathrm{C}_{\mathrm{p}}(\lambda)}{\lambda}
$$

The tip speed ratio, 8 depends on the blade Radius $\mathrm{R}$, the wind speed U4 and the rotor angular speed $\mathrm{S}_{\mathrm{r}}$ as in Eq. 8:

$$
\lambda=\frac{\mathrm{R} \Omega_{\mathrm{r}}}{\mathrm{U}_{\infty}^{2}}
$$

Therefore, including Eq. 7 and 8 into Eq. 6, the following relation results (Eq. 9):

$$
\mathrm{T}=\frac{\mathrm{P}}{\Omega_{\mathrm{r}}}=\frac{1}{2} \rho \mathrm{U}_{\infty}^{3} \mathrm{~A} \frac{\mathrm{C}_{\mathrm{q}}(\lambda)}{\Omega_{\mathrm{r}}}
$$

where, $\mathrm{C}_{\mathrm{p}}(8)$ is the power Coefficient is a nonlinear function of wind velocity and blade pitch angle and is highly dependent on the constructive features and characteristics of the turbine. It is represented as a function of the tip speed ratio 8 given by: by Slootweg et al., the power Coefficient $\mathrm{C}_{\mathrm{p}}(8)$ is expressed using Eq. 10:

$$
C_{q}(\lambda)=0.22\left(\frac{116}{\lambda_{i}}-(0.4 \theta)-5\right) e^{\frac{-12.5}{\lambda_{i}}}
$$

The tip speed ratio equivalent is calculated using Eq. 11:

$$
\lambda_{\mathrm{i}}=\frac{1}{(\lambda+0.08 \theta)}-0 \cdot \frac{035}{\theta^{3}+1}
$$

where, 2 represents the zero pitch angle.

Transmission and generator efficiencies: The shaft power output that, we have been discussing is not normally used directly but is usually coupled to a load through a transmission or gear box. The load may be a pump, compressor, grinder, electrical generator and so, on. For purposes of illustration, we will consider the load to be an electrical generator. The basic system is then as

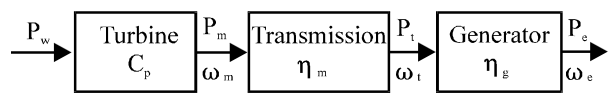

Fig. 3: Wind electric system

shown in Fig. 3. We start with the Power in the wind, $\mathrm{P}_{\mathrm{w}}$. As this power passes through the turbine, we have a mechanical Power $\mathrm{P}_{\mathrm{m}}$ at the turbine angular velocity $\mathrm{Tm}$ which is then supplied to the transmission. The transmission output Power $\mathrm{P}_{\mathrm{t}}$ is given by the product of the turbine output Power $\mathrm{P}_{\mathrm{m}}$ and the transmission efficiency $0_{\mathrm{m}}$ :

$$
P_{t}=\eta_{m} P_{m}
$$

Similarly, the generator output Power $\mathrm{P}_{\mathrm{e}}$ is given by the product of the transmission output power and the generator efficiency $\mathrm{O}_{\mathrm{g}}$ :

$$
P_{e}=\eta_{g} P_{t}
$$

Relating electrical power output to wind power input:

$$
P_{e}=C_{p} \eta_{m} \eta_{g} P_{w}
$$

At rated wind speed, the rated electrical Power output $\mathrm{P}_{\mathrm{eR}}$ can be expressed as:

$$
\mathrm{P}_{\in \mathrm{R}}=\mathrm{C}_{\mathrm{pR}} \eta_{\mathrm{mR}} \eta_{\mathrm{gR}} \frac{\rho}{2} \mathrm{Au}_{\mathrm{R}}^{3}
$$

Where:

$\mathrm{C}_{\mathrm{pR}}=$ The Coefficient of performance at the rated wind speed $\mathrm{u}_{\mathrm{R}}$

$0_{\mathrm{mR}}=$ The transmission efficiency at rated power

$0_{\mathrm{GR}}=$ The generator efficiency at rated power

The losses of transmission are due mainly to the friction due to viscosity and bearings. When the rotation speed of the turbine is constant, the losses can be considered constant. As a result, the losses can be assumed to be a percentage of the low speed shaft. About $2 \%$ was considered as reasonable value in different references (Johnson, 2001). Each ratio of the step up gear is 6:1 as maximum, three or four stages can be considered for the wind turbine. This design allows a total ratio of $36: 1$ in case of 2 stages or 216:1 in the case of three stages. The transmission efficiency can be given by Eq. 16 while $\mathrm{q}$ is the number of stages used:

$$
\eta_{\mathrm{m}}=\frac{\mathrm{p}_{\mathrm{t}}}{\mathrm{P}_{\mathrm{m}}}=\frac{\mathrm{P}_{\mathrm{m}}-(0.02) \mathrm{qP}_{\mathrm{mR}}}{\mathrm{P}_{\mathrm{m}}}
$$


where, PmR is the rated turbine shaft power (Johnson, 2001).

Three-phase rectifier: As mentioned in the previous study, the wind turbines run at variable speeds, thus, the voltage and the frequency outputs of the generator are variables. To make them constant, a rectifier is used to rectify the voltage and then the DC voltage is inverted to fixed frequency and voltage as shown in Fig. 2. Figure 4 shows the three phase rectifier which is constructed by six diodes, two for each phase. The rectifier is used to convert alternative voltage and current to direct voltage and current. The capacitor is used to support the direct voltage and keep it at a fixed value. The output of three phase rectifier is given by:

$$
\overline{\mathrm{U}_{\mathrm{d}}}=\frac{3 \sqrt{3}}{\pi} \mathrm{v}_{\text {peak }}=\frac{3 \sqrt{3}}{\pi} \sqrt{2} \mathrm{v}_{\mathrm{rms}}
$$

Where:

$\mathrm{U}_{\mathrm{d}}=\mathrm{DC}$ voltage

$\mathrm{v}_{\text {peak }}=$ Maximum AC voltage

$\mathrm{v}_{\mathrm{rms}}=$ rms value of voltage

Voltage source inverter: Voltage Source Inverters (VSI) are one of the most important applications of power electronics. The main purpose of these devices is to provide a three-phase voltage source where the amplitude, phase and frequency of the voltages should always be controllable (Rashid, 2001).

The standard three-phase two levels VSI topology is shown in Fig. 5. It is composed of three legs with current reversible switches, controlled for the open and close. These switches are realized by controlling switches (GTO

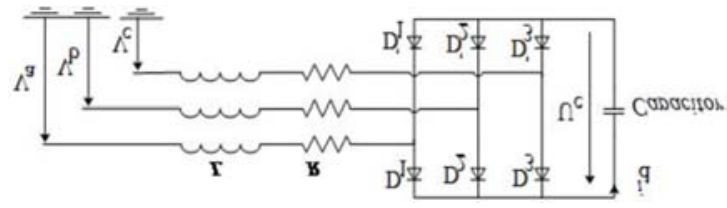

Fig. 4: Three phases rectifier

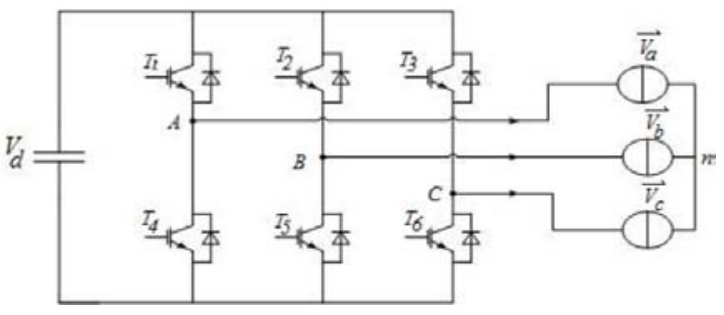

Fig. 5: Voltage Source Inverters (VSI) or IGBT) with anti-parallel diodes to allow the flow of the freewheeling currents. Simple voltages of the VSI can be given by:

$$
\left\{\begin{array}{l}
\mathrm{V}_{\mathrm{a}}=\mathrm{V}_{\mathrm{d}} \frac{2 \mathrm{~S}_{\mathrm{a}}-\mathrm{S}_{\mathrm{b}}-\mathrm{S}_{\mathrm{c}}}{3} \\
\mathrm{~V}_{\mathrm{b}}=\mathrm{V}_{\mathrm{d}} \frac{2 \mathrm{~S}_{\mathrm{b}}-\mathrm{S}_{\mathrm{a}}-\mathrm{S}_{\mathrm{c}}}{3} \\
\mathrm{~V}_{\mathrm{a}}=\mathrm{V}_{\mathrm{d}} \frac{2 \mathrm{~S}_{\mathrm{c}}-\mathrm{S}_{\mathrm{a}}-\mathrm{S}_{\mathrm{b}}}{3}
\end{array}=\{1 \text { or } 0\right.
$$

where, $\mathrm{S}_{\mathrm{a}, \mathrm{b}, \mathrm{c}}$ States of switchs. The main aim of using the rectifier with three phase voltage source inverter was to convert the AC variable frequency and amplitude voltage generated by synchronous generator into fix frequency and amplitude voltage as shown previously in Fig. 2. The generated voltage will then be connected to the grid to transmit the power from and into the power grid. In this way, the power generated by the generator is transmitted to the grid. The inverter is controlled in such a way to keep the voltage of the capacitor bank fix at a defined value. When the DC voltage is increased the power flows to the grid and if the voltage decreased the grid sends its power to the capacitor. In this way, the power is transmitted in two directions such that the resultant power is transmitted from the generator to the power grid.

\section{RESULTS AND DISCUSSION}

In this research, the three wind turbine blades are shown in Fig. 6 and the direct connection is used via. various links and gear. The turbine captures wind and moves due to the present of lift forces when we used NACA airfoil or due to the presence of pressure drag force when we use $\mathrm{C}$-section or single big $\mathrm{C}$-section blade which cause it to rotate about it fixed axis.

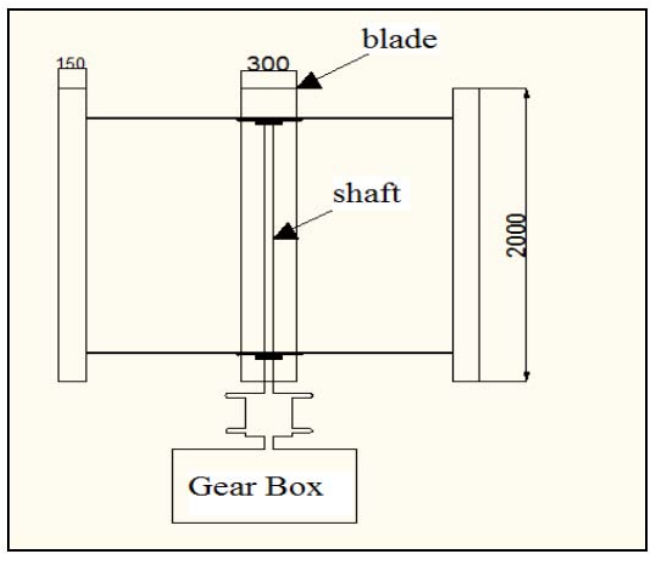

Fig. 6: Set up (front view of the turbine blades with scale is $1 \mathrm{~mm}=10 \mathrm{~cm}$ ) 
Figure $7 \mathrm{~A}$ shows the free stream velocity $\mathrm{U}_{4}$, the direction of speed of the blades (TR), the position of the blades with angle ( and the direction of rotation of the blades for different blades. During the rotation, the free stream velocity $\mathrm{U}_{4}$ has two components. First component is directed along with the velocity direction. It is used to calculate the skin friction drag force. The second component is directed perpendicular to the free stream velocity, direction and used to calculate the pressure drag force. Since, the speed of the blades affects both surfaces of the C-section and at the same time we have the free stream velocity effect on the upper or lower surface which depends on the location of the profile, the free stream velocity is added to or subtracted from the speed of the blades (TR) which depends on the direction of the velocity as shown in Fig. 7B.
Flowchart for the calculation of the forces and torques of vertical wind turbine by using different blades: The flow charts below identify the procedure to compute the drag force and torque of vertical wind turbine for NACA airfoil and different types of C-section blades (Fig. 8). Using the flow chart of four digit NACA airfoils, the change in the torque for NACA 0012 profile with angle of rotation $(()$ is shown in Fig. 9.

By using the flowchart of C-section blades, the change in torque and mechanical power for $\mathrm{C}$-section and single big C-section blade with diameter 0.3 and $1 \mathrm{~m}$, respectively is shown in Fig. 10. Figure 10b shows that single big C-section produced the maximum mechanical power which is just over $11 \mathrm{~kW}$ where (is equal 60,180 and $300^{\circ}$.
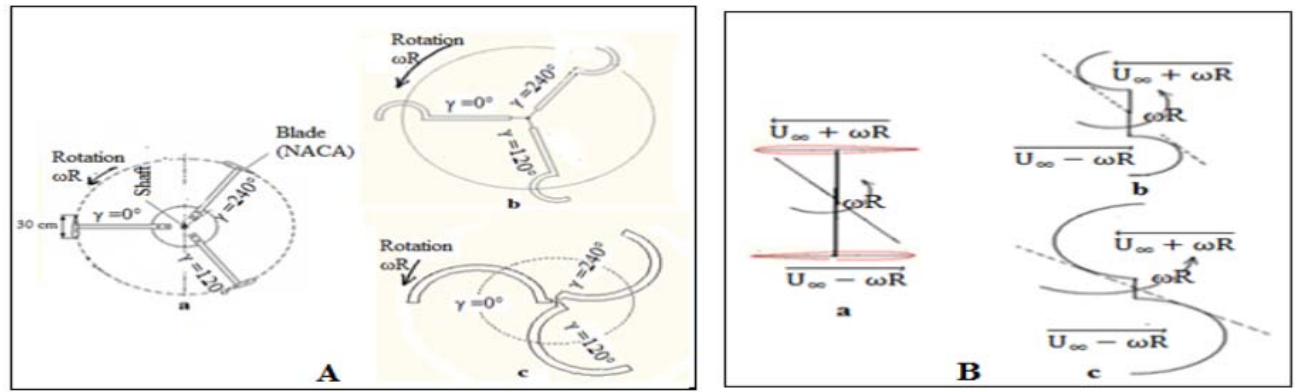

Fig. 7: A) Schematic diagram of three-blade rotor; a) NACA airfoil blade; b) C-section blade; c) Single big C-section blade and B) Schematic diagramof one-blade rotor: a) NACA airfoil blade; b) C-section blade; c) Single big C-section blade
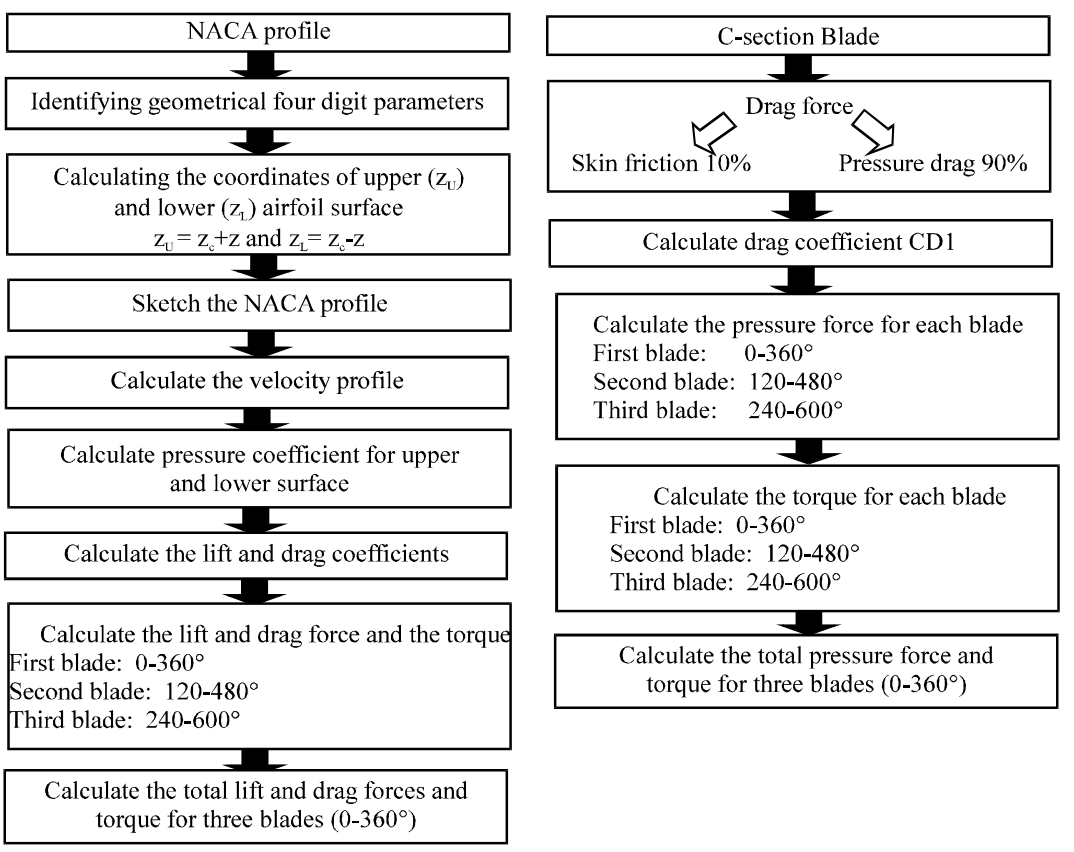

Fig. 8: Flow chart of four digit NACA airfoils 


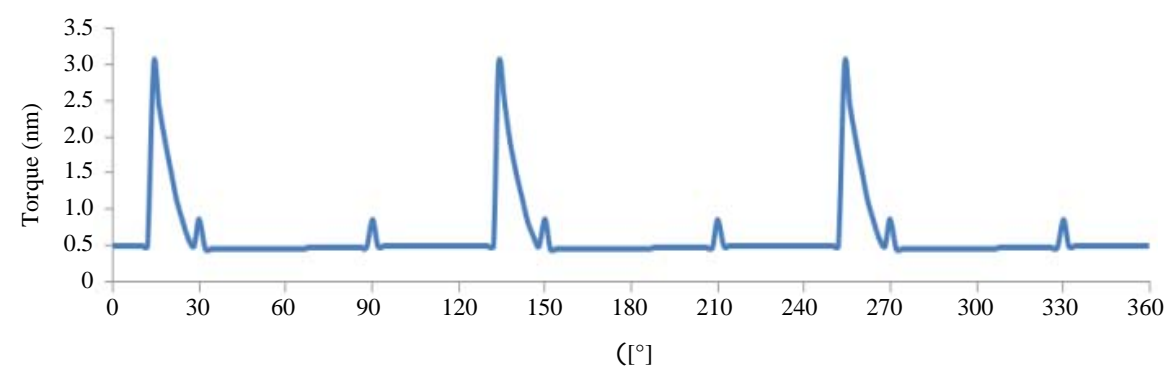

Fig. 9: Torque plot of the NACA 0012 airfoil
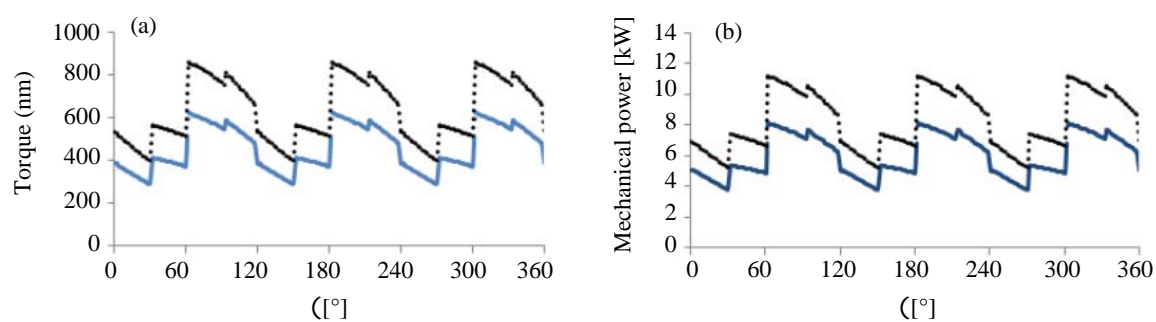

Fig. 10: Torque and mechanical power plot for; a) C-section with $D=0.3 \mathrm{~m}$ and b) Single big C-section with $\mathrm{D}=1 \mathrm{~m}$

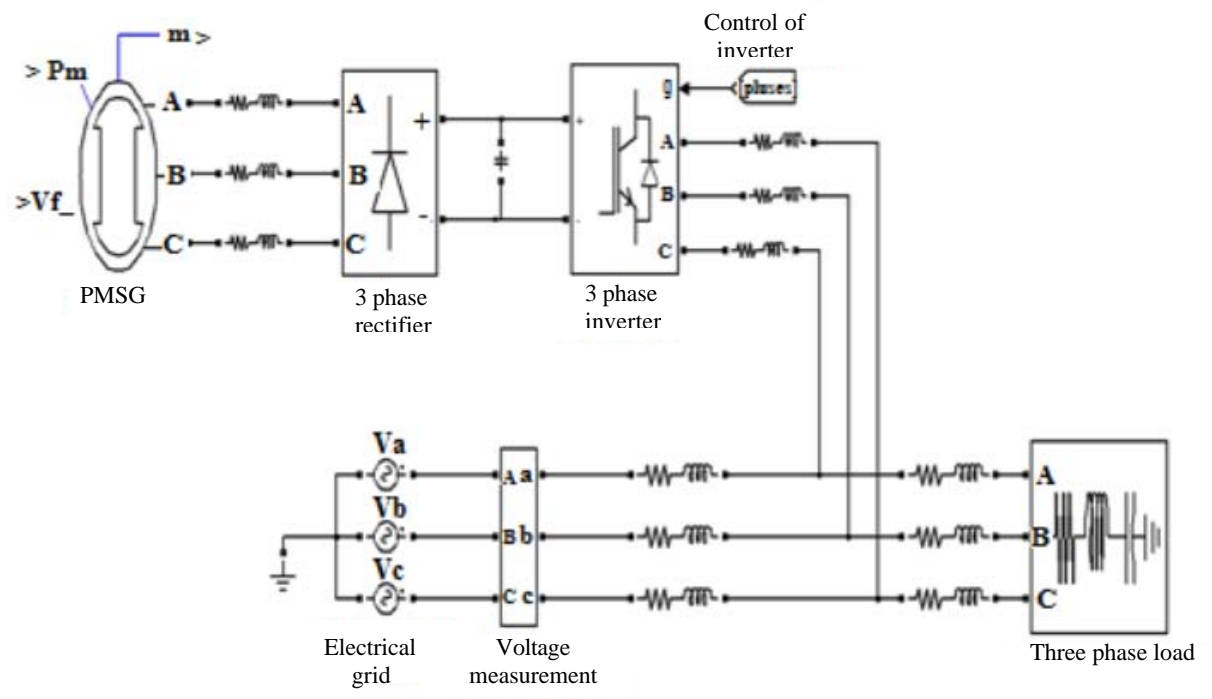

Fig. 11 The system of synchronous generator with rectifier and inverter

Permanent Magnet Synchronous Generator (PMSG): The synchronous generator is a type of electrical power generator used to generate electrical power at a fixed frequency. The rotor of PMSG is equipped with a permanent magnet to create the main magnetic field. The rotor is then turned at fixed speed using a mechanical motor. The rotor is then turned at fixed speed using a mechanical motor, air or gas turbine or any other power source. Three phase voltage will be induced in the armature windings of the synchronous machine. In our study, a present model of synchronous machine in Matlab/Simulink was used to generate three phase voltage. The voltage generated by the generator is variable with variable frequency. The variable frequency is due to the variations in wind speed and power. The voltage produced is then fed to the rectifier which produces DC voltage and then the DC voltage is converted to fixed frequency and amplitude AC voltage which can be connected directly to the grid. The system of synchronous generator with rectifier and inverter is shown in Fig. 11. 
In this case, the mechanical input power for $\mathrm{C}$-section blade was $6.032 \mathrm{~kW} / \mathrm{h}$ while the average injected power to the grid was $4.03 \mathrm{~kW} / \mathrm{h}$ with a total efficiency of $66.8 \%$. We can notice the same for the C-section and big single $\mathrm{C}$-section blade where the voltage of the inverter was same as that of the grid. The frequency of the output voltage is fixed and can be connected directly to the grid. The mechanical input power in the second case (single big C-section) was $8.3 \mathrm{kWh}$ while the average injected power to the grid was $5.542 \mathrm{~kW} / \mathrm{h}$.

\section{CONCLUSION}

In this study, several aerodynamic models have been analyzed which is applied for better performance prediction and design analysis of different types of blade for vertical wind turbine. Also, in this study a model for the evaluation of energy performance and aerodynamic forces acting on a different type of blade for vertical axis wind turbine which are depending on the blade geometrical section has been developed. The research demonstrated that single big C-section blade of a wind turbine with diameter $1 \mathrm{~m}$ can produce more mechanical power than any other blade in the lower wind speeds. The same parameters, torque and mechanical power have also been determined for different types of NACA airfoils but the results are not illustrated in the diagrams because they are too small in comparison with the results of another study cases. Also, study represented the simulation of a power electronic converter used for grid connection of a permanent magnet synchronous generator with variable-speed wind turbine. The electrical power generated by the PMSG was converted from AC to DC; an on-grid type inverter was used for the connection of the system with a $240 \mathrm{~V}$ power grid. Comparing all models, electrical output power and the highest output power was $5.542 \mathrm{~kW} / \mathrm{h}$ by using single big C-section blade. Comparing the electrical power of the C-section blade with NACA airfoils, we found the electricity produced by a NACA airfoil is approximately neglected which was nearly $0.7 \mathrm{~W} / \mathrm{h}$.

\section{REFERENCES}

Abbott, I.H. and A.E. von Doenhoff, 1959. Theory of Wing Sections, Including a Summary of Airfoil Data. Dover Publications Inc., Mineola, New York, USA., ISBN:9780486605869, Pages: 693.

Abzug, M.J. and E.E. Larrabee, 2002. Airplane Stability and Control: A History of the Technologies that Made Aviation Possible. 2nd Edn., Cambridge University Press, Cambridge, UK., ISBN-13:978-0521-80992-4, Pages: 414.
Anderson, J.D. and J.D. Anderson Jr, 1999. A History of Aerodynamics: And its Impact on Flying Machines. Cambridge University Press, Cambridge, UK., ISBN-13: 978-0521669559, Pages: 494.

Angelin, S. and S. Kraftverksforeningen, 1981. Hydro power in Sweden. The Swedish Power Association, Stockholm, Sweden.

Bianchi, F.D., H. de Battista and R.J. Mantz, 2007. Wind Turbine Control Systems: Principles, Modelling and Gain Scheduling Design. Springer, London, UK., ISBN-13:978-1-84628-492-2, Pages: 208.

EWEA., 2011. Pure Power-Wind Energy Targets for 2020 and 2030. European Wind Energy Association, Brussels, Belgium, Pages: 96.

Earnest, J., 2014. Wind Power Technology. PHI Learning, New Delhi, India, Pages: 492.

Eriksson, S., 2008. Direct driven generators for vertical axis wind turbines. Ph.D Thesis, Uppsala University, Uppsala, Sweden.

Eriksson, S., H. Bernhoff and M. Leijon, 2008. Evaluation of different turbine concepts for wind power. Renewable Sustainable Energy Rev., 12: 1419-1434.

European Wind Energy Association, 2010. Powering Europe: Wind Energy and the Electrical Grid. European Wind Energy Association, Brussels, Belgium,.

Fox, R.W., A.T. Mcdonald and P.J. Pritchard, 2002. Introduction to Fluid Mechanics. 6th Edn., John Wiley \& Sons Inc., Hoboken, New Jersey, USA.,.

Heffley, D., 2007. Aerodynamic characteristics of a NACA 4412 airfoil. MSc Thesis, Mechanical Engineering Department, Baylor University, Waco, Texas, USA.

Horiuchi, N. and T. Kawahito, 2001. Torque and power limitations of variable speed wind turbines using pitch control and generator power control. Proceedings of the Power Engineering Society Summer Meeting, July 15, 2001, IEEE., Japan, pp: 638-643.

Houghto, E.L. and P.W. Carpenter, 2003. Aerodynamics for Engineering Student. 5th Edn., ButterworthHeinemann, Great Britain, UK., ISBN:0-7506-5111-3, Pages: 614.

Iida, A., A. Mizuno and K. Fukudome, 2004. Numerical simulation of aerodynamic noise radiated form vertical axis wind turbines. Proceedings of the 18th International Congress on Acoustics (ICA'04), April 4-9, 2004, Kyoto, Japan, pp: 1311-1314.

Johnson, G.L., 2001. Wind energy systems. Manhattan, Kansas, USA. https://docplayer.net/25806236-Windenergy-systems-electronic-edition-gary-1-johnsonmanhattan-ks.html 
Khan, B.H., 2006. Non-Conventional Energy Resources. McGraw-Hill Education, India, ISBN: 9780070606548 , Pages: 335.

Kjaer, C., 2010. Why Europe needs an electricity Supergrid. Business Green, London, England. https://www.businessgreen.com/bg/opinion/18047 50/why-europe-electricity-supergrid

Kothari Et Al., 2008. Renewable Energy Sources and Emerging Technologies. Prentice-Hall of India Publications, New Delhi, India, ISBN:9788120333574, Pages: 350 .

Manwell, J.F., J.G. McGowan and A.L. Rogers, 2009. Wind Energy Explained: Theory, Design and Application. 2nd Edn., John Wiley and Sons Ltd., West Sussex, UK., ISBN-13: 9780470686287, Pages: 704.

Masters, L. and L. Duff, 2011. Overcoming Barriers to Climate Change Adaptation Implementation in Southern Africa. The Africa Institute of South Africa (AISA), Pretoria, South Africa, ISBN:978-0-7983-02951, Pages: 262.
Patel, M.R., 2006. Wind and Solar Power Systems: Design, Analysis and Operation. 2nd Edn., Taylor \& Francis, Milton Park, Didcot, UK., ISBN:9780849315701, Pages: 448.

Rashid, M.H., 2001. Power Electronics Handbook. Academic Press, Cambridge, Massachusetts, USA., ISBN-13:978-0125816502, Pages: 895.

Ribrant, J. and L.M. Bertling, 2007. Survey of failures in wind power systems with focus on Swedish wind power plants during 1997-2005. IEEE Trans. Energy Convers., 22: 167-173.

Schlichting, H.T. and E.A. Truckenbrodt, 1979. Aerodynamics of the Airplane. Mac Graw-Hill, New York, USA., ISBN: 9780070553415, Pages: 541.

Tong, W., 2010. Wind Power Generation and Wind Turbine Design. WIT Press, Southamton, England, UK., ISBN:978-1-84564-205-1, Pages: 768. 